\title{
Sobre la cronología y el papel de los vasos polípodos en Catalunya: la Balma de Pegueroles (Navès, Solsonès) y otros puntos de aparición de este elemento
}

\author{
JORDI ROVIRA I PORT
}

\section{INTRODUCCIÓN}

Nos acercamos de nuevo desde estas líneas al análisis tipológico y cronológico de un tipo cerámico -los vasos polípodos- al que se ha dedicado durante estos últimos años un cierto número de trabajos (J. Rovira, 1976; J. Rovira, 1978; M.A. Petit, J. Rovira, 1979; J.L. Maya, 1983).

Los vasos cerámicos denominados «polípodos», cuya génesis ha sido buscada en una amplia zona extendida a ambos lados del Pirineo central, con ramificaciones hacia el nordeste de la Península lbérica, sureste francés y esporádicamente hacia el Macizo central francés, han poseido un dilatado desarrollo durante el cual tan sólo han conservado como característica fundamental los elementos de los cuales toman nombre: los apéndices basales o pies.

En efecto, el análisis detenido de los ejemplares conocidos y el aña- 
dido de nuevas localizaciones permite matizar o confirmar distintos aspectos apuntados ya en publicaciones anteriores. En este sentido, tanto el identificar los ejemplares más antiguos, como la localización de las piezas polípodas del Bronce más recientes, ayudará al intento de conseguir su más exacta filiación y entender en toda su complejidad el entramado de tomas y cesiones en el intercambio de formas y decoraciones entre los distintos complejos culturales a lo largo de la Edad del Bronce.

En este trabajo aportamos comentarios sobre cuatro nuevos yacimientos que han proporcionado evidencias de vasos polípodos en Catalunya y que nos ilustran sobre ciertos aspectos de su filiación cultural y cronología.

\section{BALMA DE PEGUEROLES (NAVĖS, SOLSONĖS)}

Se trata de un yacimiento prácticamente inédito, parcialmente explorado por Joan Serra Vilaró a principios de siglo y recogido sólo a nivel cartográfico en su obra sobre el vaso campaniforme en Catalunya y las cuevas sepulcrales eneolíticas (J. Serra i Vilaró, 1923). Aunque disponemos de muy poca información, parece consistir en una típica balma sepulcral de la que se conservan en el Museo Arqueológico de Solsona tres piezas significativas: un vaso bitroncocónico, ancho de diámetro, de carena alta y angulosa, borde bien exvasado, labio plano y base umbilicada. La pieza conserva una lengüeta perforada verticalmente y quizás portase otra opuesta que no ha llegado hasta nosotros.

Junto con esta pieza se recuperó una jarra bitroncocónica de borde exvasado, labio redondeado, tercio inferior de tendencia globular y base plana. El vaso porta un asa desde el borde hasta el hombro.

Finalmente y como elemento interesante, los restos de una pieza probablemente hemisférica o quizás de perfil en ese que habia poseído varios apéndices basales o pies, perfectamente apreciables por la impronta que dejaron en la parte inferior externa de la base. Ignoramos el número de pies ni otras características del vaso.

Simultáneamente a estas tres piezas se recogieron también una falange humana y los siguientes restos de fauna: un fragmento distal derecho de metápodo de ovicáprido y dos extremos pulimentados de asta de ciervo (Cervus Elaphus). Los extremos recuperados habían pertenecido a un ejemplar macho adulto.

Uno de los ejemplares pulimentados presenta su base rota modernamente y con toda probabilidad fue tallado con una herramienta de una cierta precisión. Quizás fue pulimentado con piel o algun otro elemento 
Sobre la cronología y el papel de los vasos polípodos
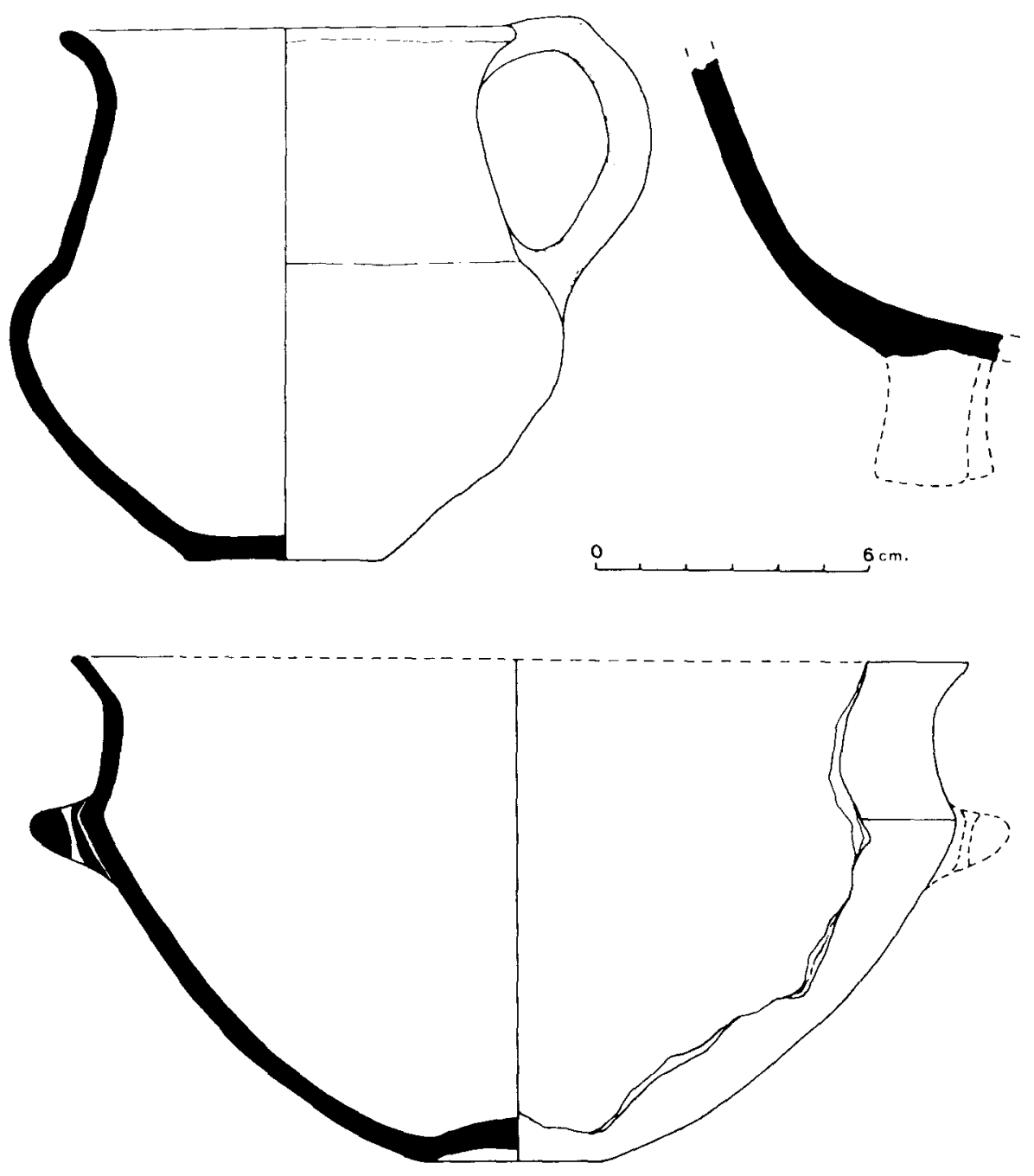

Fig 1. Materiales arqueológicos procedentes de la Balma de Pegueroles.

271 
sin grano ya que no presenta estrías visibles ni tan siquiera a cuarenta aumentos. Es probable que fuera utilizado por la punta. Longitud conservada: $38 \mathrm{~mm}$.

El otro ejemplar recuperado muestra idéntico sistema de pulimentación. Su punta fue también utilizada. Se aprecian rayados y en algunas zonas marcas de rotación, transversales, perpendiculares al eje. Hacia la zona medial es visible un pequeño piqueteado.

\section{COMENTARIO}

La primera pieza bitroncocónica de boca ancha de Pegueroles es fechable a lo largo de las primeras fases del Bronce Final, y el vaso bitroncocónico con asa a mano parece ser un predecesor de las típicas jarras bitroncocónicas a torno tan abundantes en época ibérica e iberoromana en gran parte de Catalunya.

A su vez, el fragmento de vaso polípodo localizado no permite ningún tipo de comparación o conclusión sobre su forma y filiación, aunque sí ilustra la larga cronología de este tipo cerámico en sus diversas variantes que, desde el Bronce Antiguo siguen con cierta intensidad a lo largo de las primeras fases del Bronce Final.

Finalmente, no sabemos a estas alturas ni las circunstancias en que llegaron estos materiales a las manos de Joan Serra Vilaró ni las caracteristicas generales del yacimiento de Pegueroles y tan sólo nos limitamos a utilizar por ahora la información que ofrece el poco material conservado en el Museo de Solsona.

\section{TOSSAL DE SOLIBERNAT (TORRES DE SEGRE, SEGRIÀ)}

En los niveles de las fases de transición del Bronce Medio al Bronce Final existentes en la terraza norte del yacimiento del Tossal de Solibernat se localizó un fragmento cerámico perteneciente a un vaso polípodo del que desconocemos forma y número de apéndices. Fechable en el Bronce Final inicial. 


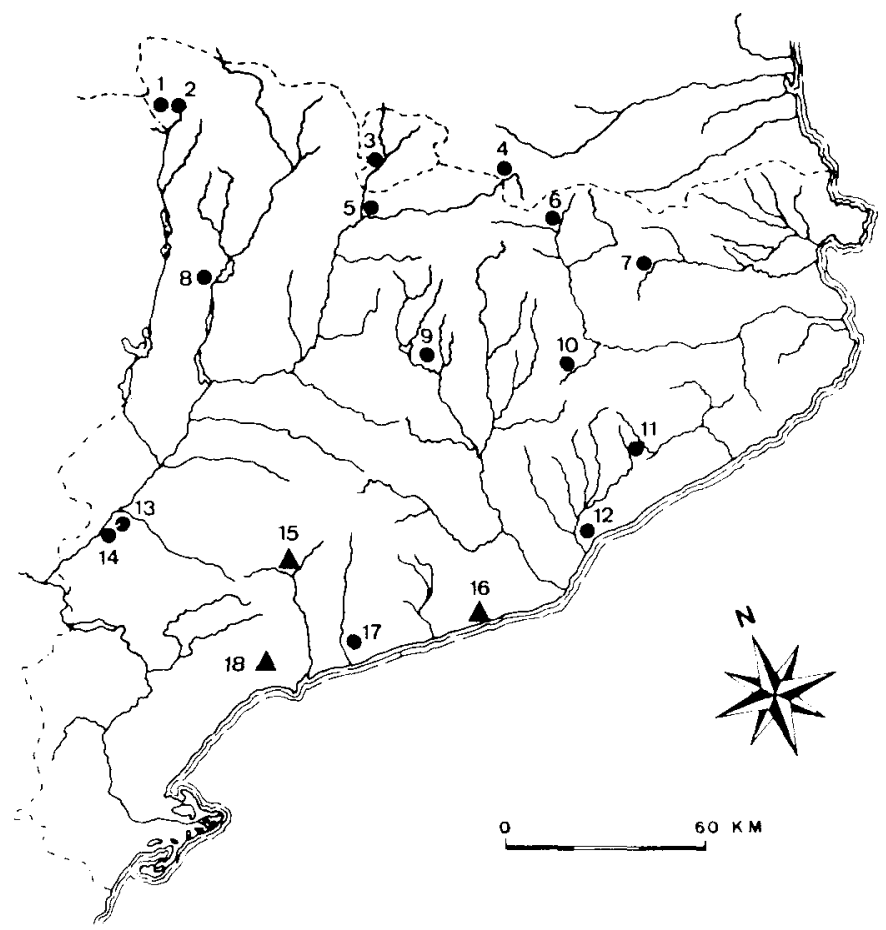

Fig 2. Mapa de dispersión de los polipodos de tipo pirenaico y derivados de éste (señalados con un punto) y de los vasos polípodos con decoración de estilo campaniforme (señalados con un triángulo).

1. Posible túmulo de Mig Aràn (Viella).

2. Posible túmulo de Cuilàs (Tredòs).

3. El Cedre VI (Sta. Coloma, Andorra).

4. Lo Lladre (St. Feliu de LLO).

5. Sepulcro La Cabana del Moro (Bescaràn).

6. Cova Gran de Rialp (Ribes de Fresser).

7. Necrópolis tumular del Pla de Gibrella (Capsec).

8. Cova de Muricecs (Llimiana).

9. Balma de Pegueroles (Navès).

10. Turó del Montgròs (El Brull).

11. Estructura de El Bruguess (St. Esteve de Palautordera).

12. Castellruf (Sta. Maria de Martorelles).

13. Tossal de Solibernat (Torres de Segre).

14. Genó (Aitona).

15. Cova del Cartanyà (Vilaverd).

16. Cova Verda (Sitges).

17. Cova Fonda (Salomó).

18. Cova M d'Arboli (Arboli). 


\section{EL BRUGUÈS (SANT ESTEVE DE PALAUTORDERA, VALLĖS ORIENTAL)}

Según la información disponible, el yacimiento podia haber consistido en un silo o en los restos más probables de alguna estructura habitacional situada en un bancal, más arriba del Forn d'en Monclús, en Sant Esteve de Palautordera, Vallès Oriental. La mayor parte de los materiales arqueológicos del lugar han desaparecido y otros se hallaban en poder de un veraneante aficionado de Sant Esteve de Palautordera desde su localización en 1954.

De entre el material recuperado y conocido cabe señalar la existencia de vasos troncocónicos con bordes decorados con impresiones y dos apéndices basales casi con toda seguridad pertenecientes a un vaso polípodo.

Así, a pesar de los pocos datos disponibles, es posible que los materiales procedan de algun tipo de estructura de habitación fechable entre el Bronce Antiguo y el Medio, con las reservas pertinentes a la información que poseemos.

\section{TURÓ DEL MONTGRÒS (EL BRULL, OSONA)}

Turó del Montgròs es el topónimo de un importante asentamiento fortificado de época ibérica en el que a principios del siglo IV antes de la Era se edificó una interesante muralla que sigue técnicas poliercéticas griegas.

Ahora bien, subyacente al asentamiento ibérico y siguiendo en parte el mismo recorrido que la muralla de los siglos IV-III a.C, aparecen las evidencias de un asentamiento anterior indigena del Bronce Final que los trabajos de los años 1974 y 1975 pusieron ya al descubierto en algunos puntos. Así, de entre los materiales fechables en el Bronce Final II de este primer momento ocupacional del lugar, hay que destacar el hallazgo de un pie de vaso polípodo del que desconocemos forma y características. No obstante, la pieza, fechable conjuntamente con el resto del material de esta fase, puede ser situada perfectamente sobre el siglo $x$ antes de la Era (A. López, J. Rovira, 1982). 


\section{CONSIDERACIONES FINALES}

A la vez que aportamos aquí algunos puntos nuevos en el mapa de distribución de los vasos polípodos del Bronce en Catalunya, hacemos hincapié en las consideraciones siguientes: por un lado, el interés que presenta la existencia de vasos polípodos en numerosos contextos y facies del Bronce Final en Catalunya, ya sea en momentos iniciales de este Bronce Final -Pegueroles, Solibernat- 0 en fases ya más avanzadas, como es el caso del Turó del Montgròs. Por su parte, los apéndices basales de El Bruguès parecen poseer aparentemente y a falta de una autopsia más directa, una cronología anterior oscilable entre el Bronce Antiguo y el Medio.

Asi, esta proliferación cada vez más acentuada de polípodos en yacimientos diversos del Bronce Final en distintas zonas meso/septentrionales de Catalunya, nos habla, de una parte, del éxito de expansión del tipo cerámico, con lo que ello implica, y, de otra parte, nos confirma el hecho ya observado con anterioridad: la persistencia del tipo cerámico y, por ende, de su complejo cultural, hasta fases avanzadas del Bronce Final y que nosotros situaríamos para los ejemplares "mas puros" en torno a la transición entre el Bronce Final II y el IIIA, o sobre el 900/875 antes de la Era.

En este sentido, es ya sabido que ciertos tipos derivados de los polipodos tradicionales perduran muy ocasionalmente en ambientes y contextos más tardios. Los casos de las necrópolis de Serrallonga o del Pla de Gibrella y, probablemente, el ejemplar de Castellruf, son ejemplos epigónicos del éxito y la difusión de un tipo cerámico pirenaico que acompaña a otros elementos culturales de la plena Edad del Bronce. Así, es comprobable en varios casos la asimilación de algunos polipodos catalanes al complejo tumular y, a la vez, podemos comprobar como, junto con los polípodos, otros elementos y materiales propios de la zona pirenaica y prepirenaica central son asimilados por grupos de la Depresión del Ebro o de la Depresión central catalana o de las zonas oriental y mesocentral. En todo caso, los polípodos más abundantes no parecen rebasar demasiado unas fechas alrededor del 900 a.C. y los ejemplares posteriores cronológicamente que puedan recibir este apelativo serán ya casos aislados y en ocasiones tipológicamente muy alejados de los prototipos originarios.

Para finalizar, apuntar que los polípodos con decoración campaniforme 0 , al revés, los vasos del complejo Campaniforme que portan pies. constituyen un complejo aparte, propio y sumamente alejado de los nú- 
cleos originarios pirenaicos. En todo caso, su papel será distinto al jugado por los polípodos pirenaicos de la Catalunya Vieja y puede estar relacionado con contactos marítimos mediterráneos que estudiaremos en otro lugar. 


\section{BIBLIOGRAFÍA}

RovirA, J., 1976: “Los vasos polípodos en Catalunya y el País Valenciano", en Cuadernos de Prehistoria y Arqueología Castellonenses. 3: 117-132.

Rovira, J., 1978: "Un vaso polípodo de la Cova Fonda de Salomó (Tarragonès, Tarragona) y los vasos polípodos de la Edad del Bronce en Catalunya", en Informació Arqueológica. 26: 11-14.

Petit, M. A. a Rovira, J., 1979: «El vaso polípodo de la Cova Verda (Sitges, Barcelona) y los polípodos con decoración de estilo campaniforme en la fachada mediterránea de la Península Ibérica", en Estudios dedicados a Carlos Callejo Serrano: 627-634.

MAYA, J. L., 1983: “Nuevos vasos polípodos pirenaicos en Cataluña”, en Trabajos de Prehistoria. 40: 59-84.

Serra Vilaro, J., 1923: El vas Campaniforme a Catalunya $i$ les coves sepulcrals eneolítiques. Solsona, Musaeum Archaeologicum Diocesanum.

Lopez, A., Rovira, J., 1982: “L'Assentament del Bronze Final del Turó del Montgròs (El Brull, Osona)", en Ausa X, XI Symposium de Prehistoria i Arqueologia Peninsular: 187-192. 